DOE-0227-2

Revision 1

\title{
Quality Assurance Plan for Transportation Management Division Transportation Training Programs
}

October 1994

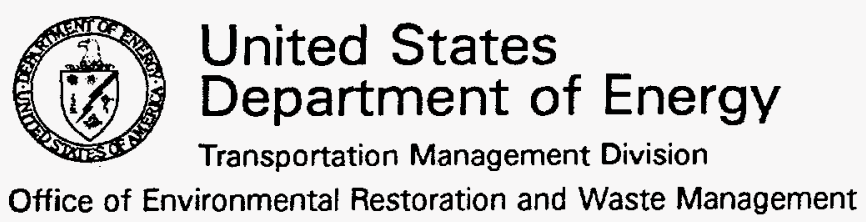
DISTRIBUTION OF THIS DOCUMENT IS UNLIMITED DSTRBUTION OF THIS DOCUMENTIS 
LEGAL DISCLAIMER

This report was prepared as an account of work sponsored by an agency of the United States Government. Neither the United States Government nor any agency thereof, nor any of their employees, nor any of their contractors, subcontractors or their employees, makes any warranty, express or implied, or assumes any legal liability or responsibility for the accuracy, completeness, or any third party's use or the results of such use of any information, apparatus, product, or process disclosed, or represents that its use would not infringe privately owned rights. Reference herein to any specific commercial product, process, or service by trade name, trademark, manufacturer, or otherwise, does not necessarily constitute or imply its endorsement, recommendation, or favoring by the United States Government or any agency thereof or its contractors or subcontractors. The views and opinions of authors expressed herein do not necessarily state or reflect those of the United States Government or any agency thereof.

This report has been reproduced from the best available copy.

Printed in the United States of America

DISCLM-2.CHP (1-91) 


\section{DISCLAIMER}

Portions of this document may be illegible in electronic image products. Images are produced from the best available original document. 
DOE-0227-2

Revision 1

\section{CONTENTS}

1.0 INTRODUCTION $\ldots \ldots \ldots \ldots \ldots \ldots$

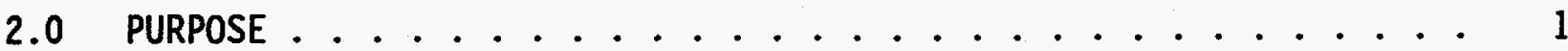

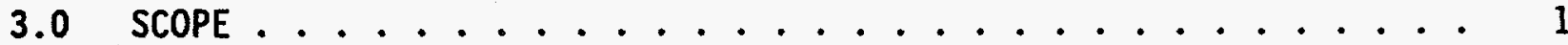

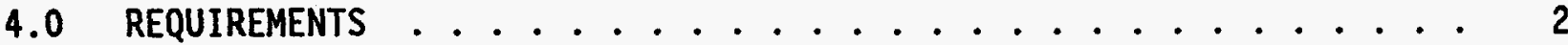

4.1 CRITERION 1 - PROGRAM ................ 2

4.1.1 Quality Assurance ............. 2

4.1.2 Organizational and Functional Responsibitities ... 2

4.1.3 Performance Criteria ............ 2

4.1.4 Definitions .............. 3

4.1.5 Control of External Processes ........... 3

4.1.6 Unsat isfactory Work ........... 3

4.2 CRITERION 2 - PERSONNEL TRAINING AND QUALIFICATION .... 3

4.2.1 Qualifications ............. 3

4.2.2 Transportation Training Programs Personnel ..... 3

4.3 CRITERION 3 - QUALITY IMPROVEMENT ............ 4

4.3.1 Processes . . . . . . . . . . . . 4

4.3.2 Training Program Performance Assessment ...... 4

4.3.3 Continuous Improvement of Processes ......... 4

4.3.4 Performance Requirements ........... 5

4.3.5 Training Program ............. 5

4.3.5.1 Errors of Consequence ......... 5

4.3.5.2 Administrative Errors ........ . 5

4.3.6 No-Fault Improvement Process .......... 5

4.3.7 Immediate Notification of Deficiencies . . . . . 6

4.3.8 Update Reviews ............... 6

4.3.9 Reviewer Qualifications ........... 6

4.4 CRITERION 4 - DOCUMENTS AND RECORDS ........... . 6

4.4.1 Document Control .............. 6

4.4.2 Revision Control ............. 6

4.4.3 Records Maintenance . . . . . . . . . . . 7

4.4.4 National Archives and Records Administration

Requirements and DOE Order 1324.2A ...... 7

4.5 CRITERION 5 - WORK PROCESSES ........... 7

4.5.1 Responsibility for Quality Work . . . . . . . . 7

4.5.2 Procedures .............. 7

4.5.3 Procedure Development ............. 7

4.5.4 Review of Procedures ............. 8

4.5.5 Regulatory Review . . . . . . . . 8

4.5.6 Materials Distribution .......... 8

4.6 CRITERION 6 - DESIGN . . . . . . . . . . . . . . 8

4.6.1 Course Design Control ............ 8

4.6.2 Federal Regulation and DOE Order Interpretation... 8

4.6.3 Program Modifications ............ 9

4.6.4 Design Interfaces .............. 9

4.6.5 Design Records . . . . . . . . . . . . . 9

4.6.6 Design Review . . . . . . . . . . . . . 9

4.6.7 Design Verification .............. 9

4.6.8 Design Acceptability ............ 10 
4.7 CRITERION 7 - PROCUREMENT . . . . . . . . . . . . . 10

4.7.1 Procurement of Materials or Services . . . . . . 10

4.7.2 Acceptance Criteria ............... 10

4.7.3 Performance Requirements ............. 10

4.7.4 Qualification of Vendors ............ 10

4.7.5 Requalification of Vendors ............ 10

4.7.6 Acceptance Process ................. . 11

4.7.7 Nonconforming Items ................ . 11

4.7.8 Performance of Purchased Items or Services . . . . . 11

4.7.9 Quality of Purchased Materials and Services..... 11

4.7.10 Substandard Items or Services ............. . 11

4.8 CRITERION 8 - INSPECTION AND ACCEPTANCE TESTING . . . . . . . . 11

4.8.1 Materials Inspection ................ 11

4.8.2 Inspection Personnel ............... 12

4.8.3 Inspection Points ............... 12

4.8.4 Defective Products . . . . . . . . . . . . . 12

4.8.5 Acceptance Testing ................ . . 12

4.9 CRITERION 9 - ASSESSMENT . . . . . . . . . . . . . 12

4.9.1 Management Assessments . . . . . . . . . . . . 12

4.9.2 Management Responsibility.............. 13

4.9.3 Assessment Documentation .. . . . . . . . . . 13

4.9.4 Follow-up to Assessments ............. 13

4.10 CRITERION 10 - INDEPENDENT ASSESSMENT . . . . . . . . . . 13

4.10.1 Assessment Scheduling ............... 13

4.10.2 Quality Improvement................ 13

4.10.3 Assessment Personne1 . . . . . . . . . . . . . 14

4.10.4 Assessment Criteria . . . . . . . . . . . . . . . 14

4.10.5 Assessment Scheduling............... . 14

4.10.6 Assessment Tracking ................. 14

4.10.7 Assessment Response ................. 14

5.0 RESPONSIBILITIES . . . . . . . . . . . . . . . . . . . 15

5.1 DIRECTOR, TRANSPORTATION MANAGEMENT DIVISION . . . . . . . . 15

$\begin{array}{ll}5.2 & \text { TRANSPORTATION MANAGEMENT DIVISION TRANSPORTATION } \\ \text { TRAINING PROGRAM MANAGER } & \cdot \cdots\end{array}$

5.3 TRANSPORTATION MANAGEMENT DIVISION - APPROVED PERSONNEL . . . 15

5.4 TRAINING PERSONNEL ................... 15

5.5 TRANSPORTATION MANAGEMENT DIVISION . . . . . . . . . 15

6.0 RESOURCE REQUIREMENTS FOR TRANSPORTATION MANAGEMENT

DIVISION TRANSPORTATION TRAINING PROGRAMS . . . . . . . . . 16

7.0 IMPLEMENTATION OF THE QUALITY ASSURANCE PLAN FOR TRANSPORTATION

MANAGEMENT DIVISION TRANSPORTATION TRAINING PROGRAMS . . . . . . 16

8.0 MEASURES OF PERFORMANCE . . . . . . . . . . . . . . . . . . 16

9.0 REFERENCES ......................... . . 17

10.0 BIBLIOGRAPHY . . . . . . . . . . . . . . . . . . . 17 


\section{LIST OF TABLES}

1. Quality Assurance Plan Implementation Milestones . . . . . . .

\section{TRAINING PROCEDURES}

1. Control of External Processes ................ . TP.1-1

2. Personnel Qualifications .............. . . TP.2-1

3. Systematic Planning . . . . . . . . . . . . . . TP.3-1

4. Modular Training Performance Evaluation and Measurement . . . . TP.4-1

5. Comment Input and Resolution . . . . . . . . . . . . . . TP.5-1

6. Regulatory Compliance Review . . . . . . . . . . . . . TP.6-1

7. Control of Documentation and Records . . . . . . . . . . . TP.7-1

8. Transportation Training Program Design . . . . . . . . . . . TP.8-1

9. Inspection and Acceptance of Transportation Training Program Materials .................... . TP.9-1

10. Management Assessment . . . . . . . . . . . . . . TP.10-1

11. Independent Assessment . . . . . . . . . . . . . . . TP.11-1 
DOE-0227-2

Revision 1

This page intentionally left blank. 


\section{QUALITY ASSURANCE PLAN FOR TRANSPORTATION MANAGEMENT DIVISION TRANSPORTATION TRAINING PROGRAMS}

\subsection{INTRODUCTION}

The U.S. Department of Transportation (DOT) implemented new rules requiring minimum levels of training for certain key individuals who handle, package, transport, or otherwise prepare hazardous materials for transportation. In response to these rules, the U.S. Department of Energy (DOE), Transportation Management Division (TMD), has developed a transportation safety training program. This program supplies designed instructional methodology and course materials to provide basic levels of DOT training to personnel for whom training has become mandatory. In addition, this program provides advanced hazardous waste and radioactive material packaging and transportation training to help personnel achieve proficiency and/or certification as hazardous waste and radioactive material shippers. This training program does not include site-specific or task-specific training beyond DOT requirements.

\subsection{PURPOSE}

This document outlines a Quality Assurance Plan (QAP) that will supply the infrastructure to ensure quality in the development and implementation of TMD transportation training program instructional methodology and course materials. The QAP will comply with the applicable requirements of 10 CFR 830.120, Quality Assurance Requirements.

\subsection{SCOPE}

The TMD training programs are developed for use by DOE staff and DOE contractors. With TMD approval, some course materials may be made available for others, including subcontractors and the private sector, for use in their training initiatives. 


\subsection{REQUIREMENTS}

\subsection{CRITERION 1 - PROGRAM}

\subsubsection{Quality Assurance}

The TMD transportation training programs shall be developed and implemented based on the requirements of 10 CFR 830.120 .

\subsubsection{Organizational and Functional Responsibilities}

Transportation training programs shall be developed under the direction and coordination of TMD, using internal resources and support from other DOE contractors. (Note: This is intended to also mean personnel delegated the responsibility of directing and coordinating training program activities with approval from TMD.) Approved personnel are responsible for requesting appropriate staff. Other DOE contractors are responsible for providing the requested staffing. Costs shall be reimbursed by TMD in accordance with established funding agreements.

Approved personnel are responsible for planning activities, developing and implementing procedures for performing work, coordinating the preparation of training methodology and course materials, and approving completed work. Approved personnel are responsible for reviewing work to ensure regulatory compliance. Internal assessments of work processes and training implementation shall be performed by internal resources, approved personnel, and responsible contractors.

\subsubsection{Performance Criteria}

Work shall be considered acceptable if it meets the following criteria:

- It is based on, and supports compliance with, DOT requirements.

- It is completed in accordance with DOE order requirements.

- It is completed by the date identified for completion.

- It is completed within resource and funding limitations imposed by TMD.

- It is user friendly and provides the appropriate levels of instructional guidance and course materials to support the effective instruction of personnel needing training to meet federal regulations, DOE orders, contractor policies and procedures, and TMD requirements. 


\subsubsection{Definitions}

Definitions for all terms used in the QAP are found in Section 5.0 of each training procedure [(1) through (11)].

\subsubsection{Control of External Processes}

Personnel approved by TMD are responsible for reviewing, approving, directing, controlling, and arranging for all external processes. These processes include printing, binding, copying, receiving of materials from subcontractors, receiving inspection, document control, distribution, and coordination and reimbursement for support services in accordance with Training Procedure (1), Section 7.0.

\subsubsection{Unsatisfactory Work}

A11 who participate in TMD transportation training program activities are responsible for (1) identifying unacceptable work performed directly for transportation training programs, (2) stopping unsatisfactory work, and (3) taking the necessary steps to ensure that work is brought into an acceptable condition. Staff members performing work for the transportation training programs are responsible for identifying and correcting unsatisfactory work if it relates to regulatory application or interpretation or for bringing it to the attention of the TMD-approved personnel for resolution coordination in accordance with Training Procedure (1), Section 7.0 .

\subsection{CRITERION 2 - PERSONNEL TRAINING AND QUALIFICATION}

\subsubsection{Qualifications}

The qualifications of personnel performing work in the development and implementation of training methodology or training course materials are identified in Training Procedure (2), Section 7.0. Records supporting personnel qualifications are maintained by TMD or TMD-approved personnel on behalf of TMD.

\subsubsection{Transportation Training Programs Personnel}

Personnel performing work on behalf of TMD shall have received training in accordance with Training Procedure (2), Section 7.0. 
DOE-0227-2

Revision 1

\subsection{CRITERION 3 - QUALITY IMPROVEMENT}

\subsubsection{Processes}

The planning process for transportation training programs shall be reviewed before implementation. The review shall be performed by someone other than the person developing the plan, in accordance with Training Procedure (3), Section 7.0.

An independent review of development and implementation activities shall be performed by someone other than the persons who are developing or implementing the training and before the preparation of the final draft. Verification of the review shall be made by TMD or TMD-approved personnel in accordance with Training Procedure (3), Section 7.0.

\subsubsection{Training Program Performance Assessment}

Approved personnel, in accordance with TMD requirements, shall evaluate the program's effectiveness using performance evaluation and measurement criteria in accordance with Training Procedure (4), Section 7.0.

On-the-job failures shall be monitored and recorded through existing DOE-approved methods (e.g., DOE Order 5000.3B). Lessons-1earned reports from contractors, training records of personnel performing work identified as a failure or incident, and training records of personnel with oversight responsibility for the personnel performing the work shall be reviewed. Costs of failure (fines, penalties, mitigation activities, litigation costs, administrative costs, repairs, cleanup, repackaging, reshipment, etc.) shal1 be identified and become part of the cost/benefit analysis for TMD transportation training programs.

\subsubsection{Continuous Improvement of Processes}

Continuous evaluation and improvement of transportation training programs shall be accomplished using input from instructors, students, and contractors. Comments shall be reviewed and incorporated or rejected as appropriate in accordance with Training Procedure (5), Section 7.0.

Training programs shall be compared annually against current regulations to ensure that changes in regulatory requirements have not invalidated the training materials. Changes in training programs shall be incorporated using the same procedures that were established for the development of the original. Reviews of changed training programs shall be performed by the same organization or staff and to the same rigor as the original program's review. Regulatory compliance review shall be performed in accordance with Training Procedure (6), Section 7.0. 
DOE-0227-2

Revision 1

\subsubsection{Performance Requirements}

The efficiency of the TMD transportation training programs shall be measured to ensure quality improvement of training plans. Test scores shall be recorded immediately following the training. The overall effectiveness of the training shall be measured using statistical analysis. Failures, or observed deviations from procedures included in the training $\mathrm{plan}$, shall be reviewed, compared with test scores, and trended.

A11 personnel performing transportation training programs work, receiving or performing training under the program, or providing oversight to personnel performing such work should be encouraged to identify weaknesses or deficiencies noted in the training program. Suggestions are invited from participants, users, or other interested or affected parties.

The basis for gathering performance-measuring information should be clear: TMD is not looking for failure or individual fault but for methods and issues to improve the quality of training programs. If a trend identifies a particular process that appears to be problematic for many, a review of the training materials, course work, comments, and evaluation inputs relating to that area shall be performed. Consultation shall be obtained from others having expertise in that specific discipline and new methods or new course work shall be developed for review and comment.

If the trend identifies a specific instructor associated with the problematic area, a review of the training methodology and the instructor shall be conducted. Additional training may be supplied to the individual training organization to improve their capabilities regarding certain issues or task-specific training may be provided by TMD.

\subsubsection{Training Program}

4.3.5.1 Errors of Consequence. When errors of consequence occur that violate regulatory requirements, they shall be corrected in a timely manner, commensurate with importance. For errors of consequence, training program methodology and course materials shall be updated immediately. When errors of consequence or significant changes in regulations occur, training modules and course materials shall be revised, updated, and redistributed in accordance with requirements for revision, update, and initial distribution. Errors shall be handled in accordance with Training Procedure (6), Section 7.0 .

4.3.5.2 Administrative Errors. Modules containing typographical errors or errors of little consequence shall be updated at the time of automatic review. The changes in regulatory requirements or changes of substantial consequence will be made in accordance with Training Procedure (6), Section 7.0.

\subsubsection{No-Fault Improvement Process}

When errors, deficiencies, or defects are identified, assignment of fault shall be avoided and the update process shall be initiated. 
If expert opinions differ on application, interpretation, or intent of regulations, TMD or TMD-approved personne?, in accordance with TMD

requirements, shall resolve the differences and identify the solution to be implemented.

\subsubsection{Immediate Notification of Deficiencies}

Instructors shall be notified immediately of significant deficiencies when: (1) the failures or deficiencies are noted but their causes are not known or (2) their causes are known but transportation training programs have not yet been updated and reissued. (See Training Procedure (6), Section 7.0.)

\subsubsection{Update Reviews}

When updates or corrections are prepared for the training program, the same level and standard of review as used for the original should be used, in accordance with Training Procedure (6), Section 7.0.

\subsubsection{Reviewer Qualifications}

The qualifications of personnel reviewing and approving training program materials and modules should be identified and documented in accordance with Training Procedure (2), Section 7.0.

\subsection{CRITERION 4 - DOCUMENTS AND RECORDS}

\subsubsection{Document Control}

Documents created for use in transportation training programs shall be developed, approved, and controlled to ensure that only complete and current materials are distributed for use. Documents in the process of revision will be available for use.

Training Procedure (7), Section 7.0, identifies how documents are identified, tracked, and kept current.

\subsubsection{Revision Control}

Following review and approval, as identified in Training Procedure (7), Section 7.0, revised documents must be subjected to the same level of control as the documents that are being revised. Revisions shall be identified within the document control system using Training Procedure (7), Section 7.0. 
DOE-0227-2

Revision 1

\subsubsection{Records Maintenance}

Records supporting the activities and tasks that occurred in the development and implementation of transportation training programs shall be maintained. Records shall include documentation of processes used, information gathered, and background data used as the basis for critical planning or decision making. Source documents, baseline studies, personnel records, and distribution records are included in the records that identify the critical records that must be maintained in accordance with Training Procedure (7), Section 7.0. Applicable requirements documents provide the period of time that the records will be maintained and the methods for records validation, control, storage, and retrieval.

\subsubsection{National Archives and Records Administration Requirements and DOE Order 1324.2A}

Guidelines for records maintenance are contained in the National Archives and Records Administration (NARA) requirements and DOE Order 1324.2A, Records Disposition. The records maintenance program used for the transportation training programs shall comply with those guidelines as required.

\subsection{CRITERION 5 - WORK PROCESSES}

\subsubsection{Responsibility for Quality Work}

Personnel and staff performing work in support of transportation training programs are responsible for the quality of their own work. Each person preparing a product or performing any support function for a training program should be knowledgeable about the desired end result of the program and the effect of their individual work on achieving that result.

Personnel and staff performing work affecting transportation training programs should be educated to understand their role in the development and implementation of a quality product in accordance with Training Procedure (2), Section 7.0.

\subsubsection{Procedures}

A11 work processes affecting the quality of the end product shall be done using documented procedures. Procedures used will become part of the records supporting transportation training programs and will be considered controlled documents and controlled records in accordance with Training Procedure (7), Section 7.0.

\subsubsection{Procedure Development}

Procedures relating to the activities of transportation training programs shall be developed by staff with the technical competence necessary to generate effective procedures. 
DOE-0227-2

Revision 1

\subsubsection{Review of Procedures}

Procedures developed to support transportation training program activities shall be verified, validated, and approved by staff not responsible for procedure development with the appropriate levels of expertise to identify shortcomings or deficiencies in procedures before implementation. Responsible individuals or managers may be able to identify problem areas or better ways to achieve organizational goals.

\subsubsection{Regulatory Review}

A process to ensure that regulations are reviewed in a timely manner, changes are noted, and appropriate steps are taken to incorporate the changes into transportation training programs is critical. This process is documented in Training Procedure (6), Section 7.0.

\subsubsection{Materials Distribution}

A process to distribute controlled instructional and course materials to instructors is essential to ensure that up-to-date materials are in use and to locate materials that require update before further use. This process is in Training Procedure (7), Section 7.0.

\subsection{CRITERION 6 - DESIGN}

\subsubsection{Course Design Control}

Training materials shall be designed in accordance with federal regulations, DOE orders, TMD requirements, and any other applicable requirements. Before the development of training methodology and course materials, all applicable requirements shall be reviewed and a process implemented to develop the instructional and course materials in compliance with those requirements. The process for transportation program design is found in Training Procedure (8), Section 7.0.

The process for design of materials shall include identification of regulatory drivers; sources of input into transportation training programs; procedures used to design the instructional and course materials; methods of updating or identifying changes to the design process; and the description of organizational interfaces, authorities, and responsibilities.

\subsubsection{Federal Regulation and DOE Order Interpretation}

Requirements from DOE orders and applicable regulations must be correctly interpreted, translated, and implemented into transportation training programs, in accordance with Training Procedure (6), Section 7.0. 


\subsubsection{Program Modifications}

Modifications to the basic requirements for transportation training programs or to basic regulatory interpretation or application shall be identified to TMD directly or via TMD-approved personnel for review and appropriate approvals. Identified modifications shall be justified and shall not be implemented before review and the receipt of written approval to implement the modification in accordance with Training Procedure (8), Section 7.0 .

\subsubsection{Design Interfaces}

Interfaces used in instructional course design work shall be identified, responsibilities and authorities defined, and interfaces controlled and coordinated in accordance with Training Procedure (8), Section 7.0. Procedures for the development of training programs shall include identification of design interfaces, authorities, and responsibilities. The data shall become part of the program's records.

\subsubsection{Design Records}

Records of design processes, source data used in design, and documentation of the early steps in the development process shall become part of the design records that must be maintained for records identification, control, maintenance, and storage in accordance with Training Procedure (8), Section 7.0.

\subsubsection{Design Review}

The steps used in developing the design process shall be reviewed and regulatory compliance of design outputs shall be verified and validated. Products of the design process shall achieve the goals of the transportation training program and should be designed to support ease of use and regulatory compliance in accordance with Training Procedure (8), Section 7.0.

\subsubsection{Design Verification}

Design review and verification shall be performed by qualified individuals or organizations who are not responsible for the design development. Verification should ensure that instructional materials and course work comply with identified design requirements and procedures. The level of effort for the verification process should be commensurate with the potential for liability in case the training should fail.

The qualifications of design reviewers and verifiers should be identified and maintained by TMD in accordance with Training Procedure (2), Section 7.0. 
DOE-0227-2

Revision 1

\subsubsection{Design Acceptability}

Design acceptability shall be completed before course materials are distributed or used in accordance with Training Procedure (8), Section 7.0.

\subsection{CRITERION 7 - PROCUREMENT}

\subsubsection{Procurement of Materials or Services}

Procurement of materials from vendors shall be obtained using DOE-approved procurement procedures. Purchasing documents shall identify inspection methods and requirements that must be met before acceptance of materials in accordance with Training Procedure (9), Section 7.0.

Procurement of vendor services shall be obtained using DOE-approved procurement procedures for obtaining services. Purchasing documents should identify requirements for acceptance and evaluation of services in accordance with Training Procedure (9), Section 7.0.

\subsubsection{Acceptance Criteria}

Acceptance criteria for the procurement of materials or services shall be included in purchasing documents and provided to the vendor before delivery of materials or services in accordance with Training Procedure (9), Section 7.0.

\subsubsection{Performance Requirements}

Performance requirements for purchased materials or services shall be identified to the vendor before the selection, determination, evaluation, and receipt of materials in accordance with Training Procedure (9), Section 7.0.

\subsubsection{Qualification of Vendors}

Only qualified vendors shall be used to obtain materials or services. Requirements for vendor qualification shall be identified and reviewed before contracting for the materials or services in accordance with Training Procedure (9), Section 7.0.

\subsubsection{Requalification of Vendors}

Qualified vendors should be monitored periodically to ensure acceptable performance in accordance with Training Procedure (9), Section 7.0. 
DOE-0227-2

Revision 1

\subsubsection{Acceptance Process}

The acceptance process for items or services should be based on industry requirements and should include identification, documentation, and verification that the process has been completed in accordance with Training Procedure (9), Section 7.0.

\subsubsection{Nonconforming Items}

Before any purchased items are distributed or used, inspection shall be performed to ensure that the items meet design or performance requirements. Nonconforming items shall be properly identified, segregated, and dispositioned in accordance with the appropriate procedures identified in Training Procedure (9), Section 7.0.

\subsubsection{Performance of Purchased Items or Services}

Actual performance of materials or services should be compared with the original performance or acceptance criteria to determine the effectiveness of the procurement and the capabilities of the supplier to supply appropriate products or services in accordance with Training Procedure (9), Section 7.0.

\subsubsection{Quality of Purchased Materials and Services}

The quality of purchased materials and services shall be verified periodically to ensure that ongoing procurement of similar materials or services continues to meet specifications and identified requirements. Re-evaluation of supplier quality should be documented and available to ensure that subsequent procurements are not placed with suppliers whose level of quality is not consistent (Training Procedure (9), Section 7.0).

\subsubsection{Substandard Items or Services}

If suppliers knowingly supplied substandard items or services, procurement information and documentation shall be forwarded to the DOE, office of Inspector General.

\subsection{CRITERION 8 - INSPECTION AND ACCEPTANCE TESTING}

\subsubsection{Materials Inspection}

Methods of inspecting procured items received from suppliers and final products created in house shall be established and documented. Requirements and methods of inspection for course materials shall be identified and documented in accordance with Training Procedure (9), Section 7.0. 


\subsubsection{Inspection Personnel}

Personnel should not inspect their own work for acceptance. The level and complexity of inspection should be commensurate with the level of risk of potential failure. Independent inspection and review of completed instructional and course work shall be performed in accordance with Training Procedure (9), Section 7.0.

\subsubsection{Inspection Points}

Planning should include hold points. These points would be used to perform inspections and identify characteristics of acceptable materials in accordance with Training Procedure (9), Section 7.0. Inspection techniques, acceptance criteria, and organizational and functional responsibilities should be identified for performing inspections.

\subsubsection{Defective Products}

When acceptance criteria are not met, deficiencies shall be resolved and reinspection shall occur in accordance with Training Procedure (9), Section 7.0. Steps to resolve the deficiencies or justification for accepting the deficiencies shall be included in the transportation training program records.

\subsubsection{Acceptance Testing}

Acceptance testing shall be performed to ensure that the final products perform as intended. Results from acceptance testing shall be prepared and shall become part of the transportation training programs' records. Documentation and implementation of acceptance testing will be done in accordance with Training Procedure (9), Section 7.0.

\subsection{CRITERION 9 - ASSESSMENT}

\subsubsection{Management Assessments}

Management assessments shall be performed to ensure that instructional methodology and course materials are prepared in accordance with the requirements of this QAP, DOE orders, and other regulations and requirements. The assessments shall be scheduled annually and shall be used as part of the quality improvement process to identify problems that hinder the effectiveness of transportation training programs. (See Training Procedure (10), Section 7.0.) 
DOE-0227-2

Revision 1

\subsubsection{Management Responsibility}

The TMD, personnel approved by TMD, and other contractors participate in assessments and share responsibility for performing or arranging for internal assessments. These assessments shall be performed in accordance with Training Procedure (10), Section 7.0.

\subsubsection{Assessment Documentation}

Internal assessments shall be documented. The TMD, and TMD-approved personnel, shall take prompt action in documenting decisions and actions implemented in response to assessments. Documentation shall be in accordance with Training Procedure (10), Section 7.0.

\subsubsection{Follow-up to Assessments}

Approved personnel are responsible for tracking and reporting to TMD follow-up actions in response to assessment findings and observations. Documentation supporting actions taken and justification for not acting shall be prepared and shall become part of the transportation training program records in accordance with Training Procedure (10), Section 7.0.

\subsection{CRITERION 10 - INDEPENDENT ASSESSMENT}

\subsubsection{Assessment Scheduling}

Independent assessments shall be performed periodically by personnel independent of transportation training program activities. These assessments shall be planned by TMD in accordance with Training Procedure (11), Section 7.0. Assessments will be performance based, ensuring regulatory compliance, but will focus on achievement of programmatic goals and objectives.

\subsubsection{Quality Improvement}

Independent assessments are designed to improve quality and verify compliance with this QAP, applicable regulations, and DOE orders. Assessments should (1) identify abnormal performance or potential problems that are observed in the use of instructional materials or course work, (2) identify methods for improving the quality of the transportation training program, (3) report results to a level of management with the authority to make changes and improvements in transportation training program effectiveness, and (4) ensure that deficient or problem areas identified in prior assessments or observations are addressed. 


\subsubsection{Assessment Personnel}

Personnel performing independent assessments shall be technically knowledgeable of the subject matter and understand the quality requirements that apply to the program in accordance with Training Procedure (11), Section 7.0 .

Personnel performing independent assessments must not have any direct responsibility in the development or implementation of the transportation training program being assessed.

\subsubsection{Assessment Criteria}

Assessment criteria should be identified before the assessment begins and should describe the requirements for acceptable work and promote improvement. Assessment requirements shall be communicated to TMD, or TMD-approved personnel, for dissemination to appropriate TMD staff to ensure their understanding of the requirements for the performance of their tasks.

\subsubsection{Assessment Scheduling}

Assessments should be scheduled at appropriately spaced intervals to ensure the continued quality of the transportation training program activities. Assessments should not be conducted so frequently as to become burdensome to the transportation training program developers, instructors, management, or TMD. Assessments shall be made in accordance with Training Procedure (11), Section 7.0. The rigor of the assessment should be commensurate with the potential for failure. Time to perform assessments should be sufficient to ensure the in-depth review of the activity being assessed but flexible enough to be able to move among areas where greater or lesser rigor is appropriate.

\subsubsection{Assessment Tracking}

Assessment results shall be tracked by approved personnel and provided to TMD. Follow-up review of deficient areas shall be initiated by responsible organizations, and reports shall be provided to TMD directly or via TMD-approved personnet.

\subsubsection{Assessment Response}

Approved personnel shall be involved on behalf of TMD in response to assessments (both internal and independent). Responses shall include, as applicable, actions to correct deficiencies, root cause identification and analysis, actions taken to prevent recurrence, lessons learned, and actions to be taken for quality improvement. 


\subsection{RESPONSIBILITIES}

\subsection{DIRECTOR, TRANSPORTATION MANAGEMENT DIVISION}

UItimate responsibility for the compliance and efficiency of TMD transportation training programs belongs to the Director, Transportation Management Division.

\subsection{TRANSPORTATION MANAGEMENT DIVISION TRANSPORTATION TRAINING PROGRAM MANAGER}

The TMD Transportation Training Program Manager is responsible for development of overall departmental policies and uniform approaches to ensure that DOE and contractor transportation functions are consistently performed in compliance with applicable laws, regulations, and DOE orders.

\subsection{TRANSPORTATION MANAGEMENT DIVISION - APPROVED PERSONNEL}

TMD-approved personnel are responsible for the development, deployment, implementation, and coordination of TMD transportation training programs.

TMD-approved personnel are responsible for participating in internal (or management) assessments of TMD transportation training programs. Approved personnel are also responsible for communicating results of internal (or management) assessments to TMD.

\subsection{TRAINING PERSONNEL}

Training personnel (e.g., TMD Instructors, TMD Associate Instructors) who are responsible for development and execution of the training process.

\subsection{TRANSPORTATION MANAGEMENT DIVISION}

TMD is responsible for reviewing the results of independent assessments of transportation training programs.

NOTE: Detailed responsibilities are found in Section 6.0 of each training procedure [(1) through (11)]. 
DOE-0227-2

Revision 1

\subsection{RESOURCE REQUIREMENTS FOR TRANSPORTATION MANAGEMENT DIVISION TRANSPORTATION TRAINING PROGRAMS}

Resources are supported by direct funding from TMD.

Resources, identified by TMD-approved personnel, are obtained through a TMD-approved procurement process and are reimbursed through the direct funding process by TMD.

\subsection{IMPLEMENTATION OF THE QUALITY ASSURANCE PLAN FOR TRANSPORTATION MANAGEMENT DIVISION TRANSPORTATION TRAINING PROGRAMS}

Implementation is dependent upon resource allocations and availability. The QAP implementation milestones are identified in Table 1.

Table 1. Quality Assurance Plan Implementation Milestones.

\begin{tabular}{|l|c|}
\hline \multicolumn{1}{|c|}{ Milestone } & Date \\
\hline Begin work on QAP infrastructure & $8 / 5 / 92$ \\
\hline Completion of draft QAP & $09 / 16 / 92$ \\
\hline Complete draft of QAP and Training Procedures & $2 / 08 / 93$ \\
\hline QAP, Revision 0 issue date & $10 / 01 / 93$ \\
\hline QAP, Revision 1 issue date & $10 / 01 / 94$ \\
\hline
\end{tabular}

\subsection{MEASURES OF PERFORMANCE}

The following measures of performance will be used to evaluate the TMD transportation training program.

- Absence of incidents that lead or could lead to DOT penalty actions.

- Absence of occurrence reports relating to hazardous materials packaging or transportation violations or potential violations. 
DOE-0227-2

Revision 1

- Successful completion of initial training by students and at identified intervals thereafter.

- Ease of understanding and implementation by instructors.

- Absence of negative findings and observations during internal (management) and independent assessments.

- Absence of negative findings and observations during Technical Safety Appraisals of contractor activities.

- Absence of DOT or transportation-related U.S. Environmental Protection Agency actions against DOE contractors after participation in TMD transportation training programs.

\subsection{REFERENCES}

10 CFR 830.120, Quality Assurance Requirements.

DOE Order 5000.3B, Occurrence Reporting and Processing of Operations Information.

DOE Order 1324.2A, Records Disposition.

National Archives and Records Administration.

\subsection{BIBLIOGRAPHY}

DOE Order 5480.19 , Conduct of Operations.

DOE Order 5480.20, Training Requirements for Nuclear Facilities.

49 CFR, Transportation, applicable Parts 0 to 199, and Parts 350 and 399. 
D0E-0227-2

Revision 1

This page intentionally left blank. 
DOE-0227-2

Revision 1

\section{QUALITY ASSURANCE PLAN FOR TRANSPORTATION MANAGENENT DIVISION TRANSPORTATION TRAINING PROGRAMS}

Title: Control of External Processes

Number: Training Procedure 1

Revision: 1

Date: $\quad 10-01-94$

\subsection{PURPOSE}

This procedure establishes Quality Assurance (QA) requirements for control of external processes.

\subsection{SCOPE}

This procedure establishes QA requirements for control of work performed by other entities in support of the U.S. Department of Energy (DOE), Transportation Management Division (TMD), transportation training programs. Work performed that requires QA control includes, but is not limited to, the following:

- Printing

- Binding

- Copying

- Receipt of training materials from subcontractors

- Receipt inspection of training materials

- Acceptance of training materials

- Document control

- Product review

- Records management

- Distribution of training materials

- Reimbursement for support services.

\subsection{APPLICABILITY}

This procedure applies to external processes performed in support of TMD transportation training programs. 
DOE-0227-2

Revision 1

\subsection{SOURCE REQUIREMENTS}

- 10 CFR 830.120, Quality Assurance Requirements

- DOE Order 1324.2A, Records Disposition.

\subsection{DEFINITIONS}

- Condition Adverse to Quality. A term used in reference to failures, malfunctions, deficiencies, defective items, and nonconformances. A significant condition adverse to quality is one that, if uncorrected, could have a serious effect on safety or operability.

- Contractor. Any contractor, supplier, seller, subcontractor, vendor, consultant, agent, agencies, or institution performing work associated with TMD transportation training programs.

- TMD-Approved Personnel. Personnel appointed by TMD who are responsible for coordinating TMD transportation training program development and implementation activities. Approved personnel also coordinate the resolution of occurrences where unsatisfactory work is identified.

- Procurement Document. Purchase requisitions, purchase orders, drawings, contracts, specifications, or instructions used to define requirements for purchase of materials or services.

- Supplier. Any individual or organization who furnishes materials or services in accordance with a procurement document. An allinclusive term used in place of vendor, seller, contractor, subcontractor, fabricator, consultant, and associated subtier levels.

- TMD Instructors and Associate Instructors. Personnel approved by TMD to develop and administer TMD transportation training programs.

\subsection{RESPONSIBILITIES}

- TMD. Approves all technical support subcontracts issued for performance of TMD transportation training program development and implementation.

- TMD Instructors and Associate Instructors. Verifies that supplies, services, and activities associated with the development and implementation of TMD transportation training programs meet established requirements. 
- TMD-Approved Personnel. Coordinates TMD transportation training program development and implementation. Interfaces with contractors, subcontractors, and TMD to ensure resources, funding, and approval requirements are in place before and during the training program development and implementation process.

\subsection{PROCEDURE}

- Instructors and developers of TMD transportation training programs shall ensure the following.

- External work performed in support of TMD transportation training programs shall be controlled in accordance with DOE orders, contractor policies and procedures, and TMD requirements.

- Procurement documents prepared in support of TMD transportation training programs shall be prepared, reviewed, and approved in accordance with appropriate procedures, requirements, and regulations.

- Materials and services that support TMD transportation training programs shall be purchased, accepted, or rejected according to federal regulations, DOE orders, contractor policies and procedures, and TMD requirements to ensure acceptable performance.

- Information, materiais, and services developed or prepared by suppliers in support of TMD transportation training programs shall be judged accurate and acceptable for use, based on visual or other approved means of inspection, in accordance with program needs before issuance.

- Prospective suppliers who perform external work shall be evaluated periodically to ensure that only qualified suppliers are selected.

- Authorized suppliers of external work shall be monitored to ensure that acceptable items and services continue to be supplied.

- Information, materials, or services prepared in support of TMD transportation training programs that are judged inadequate and considered "adverse to quality," shall be documented in accordance with appropriate reporting requirements. Approved corrective action management techniques shall be used to document and correct a11 deficiencies, defective items, and nonconformances. 
- Documentation and records associated with external work performed in support of TMD transportation training programs shall be controlled in the following manner.

- Documentation and records shall be distributed, handled, and controlled in accordance with approved contractor policies and procedures and in accordance with applicable DOE orders and TMD requirements (DOE Order 1324.2A).

- Documentation and/or records that are considered "Quality Records" shall be specified in applicable program documents. "Quality Records" shall be legible, accurate, and completed as appropriate for the activity that is being accomplished. 
DOE-0227-2

Revision 1

\section{QUALITY ASSURANCE PLAN FOR TRANSPORTATION MANAGEMENT DIVISION} TRANSPORTATION TRAINING PROGRAMS

$\begin{array}{ll}\text { Title: } & \text { Personnel Qualifications } \\ \text { Number: } & \text { Training Procedure } 2 \\ \text { Revision: } & 1 \\ \text { Date: } & 10-01-94\end{array}$

\subsection{PURPOSE}

This procedure establishes Quality Assurance (QA) requirements for personnel qualifications.

\subsection{SCOPE}

This procedure provides a method for identification, review, and documentation of qualifications for personnel involved with the development and implementation of U.S. Department of Energy (DOE), Transportation Management Division (TMD), transportation training programs. Personnel who must be qualified include TMD Instructors and TMD Associate Instructors.

\subsection{APPLICABILITY}

This procedure applies to qualification of personnel developing and implementing TMD transportation training programs.

\subsection{SOURCE REQUIREMENTS}

- 10 CFR 830.120, Quality Assurance Requirements

- DOE Order 1324.2A, Records Disposition

- 49 CFR, Transportation, applicable Parts 0 to 199, and Parts 350 to 399. 


\subsection{DEFINITIONS}

- Contractor. Any contractor, supplier, seller, subcontractor, vendor, consultant, agent, or institution performing work associated with TMD transportation training programs.

- TMD-Approved Personnel. Personnel appointed by TMD who are responsible for coordinating TMD transportation training program development and implementation activities. Approved personnel also coordinate the resolution of occurrences where unsatisfactory work is identified.

- TMD Instructors and Associate Instructors. Personnel approved by TMD to develop and administer TMD transportation training programs.

\subsection{RESPONSIBILITIES}

- TMD. Directs and sponsors a11 TMD transportation training programs. Approves all technical support subcontracts issued for performance of TMD transportation training program development and implementation.

- IMD-Approved Personnel. Coordinates TMD transportation training program development and implementation. Interfaces with contractors, subcontractors, and TMD to ensure resources, funding, and approval requirements are in place before and during the training program development and implementation process.

- IMD Instructors and Associate Instructors. Administers TMD transportation training programs. Administers learning measurement exercises (tests) and validates successful completion.

\subsection{PROCEDURE}

- Transportation training programs shall be developed, implemented, and administered by trained and qualified personnel as prescribed by TMD. Minimum qualifications established for training program instructors and developers are as follows.'

- TMD-approved transportation training program instructors should meet the following criterion.

${ }^{1}$ TMD Associate Instructors should meet qualifications within a flexible time period based on ski71, experience, and education. 
Table A.2-1. Instructor Presentation Skills.

\begin{tabular}{|l|l|l|}
\hline \multicolumn{1}{|c|}{ Presentation Ski11 } & \multicolumn{1}{|c|}{ TMD Instructor } & \multicolumn{1}{|c|}{$\begin{array}{c}\text { TMD Associate } \\
\text { Instructor } \\
\text { (Team Teach OnTy) }\end{array}$} \\
\hline $\begin{array}{l}\text { Performance based } \\
\text { instructor training } \\
\text { (basic) }\end{array}$ & Required & $\begin{array}{l}\text { Required prior to or } \\
\text { commensurate with } \\
\text { instruction of TMD } \\
\text { courses }\end{array}$ \\
\hline $\begin{array}{l}\text { Performance based } \\
\text { instructor training } \\
\text { (advanced) }\end{array}$ & Required & N/A \\
\hline Instructor experience & 200 hours required & N/A \\
\hline Instructor training & N/A & $\begin{array}{l}80 \text { hours of } \\
\text { structured classroom } \\
\text { observation }\end{array}$ \\
\hline
\end{tabular}

TMD = Transportation Management Division.

Table A.2-2. Course Development.

\begin{tabular}{|l|l|c|}
\hline Development of courses & \multicolumn{1}{|c|}{ TMD Instructor } & \multicolumn{1}{|c|}{$\begin{array}{c}\text { TMD Associate } \\
\text { Instructor } \\
\text { (Team Teach Only) }\end{array}$} \\
\hline $\begin{array}{l}\text { New course development } \\
\text { or revision of existing } \\
\text { course }\end{array}$ & $\begin{array}{l}\text { Lead responsibility } \\
\text { for development or } \\
\text { revision of TMD } \\
\text { courses }\end{array}$ & N/A \\
\hline $\begin{array}{l}\text { Annual review/update of } \\
\text { course material }\end{array}$ & $\begin{array}{l}\text { Participation in at } \\
\text { least one annual } \\
\text { review/update }\end{array}$ & N/A \\
\hline
\end{tabular}

TMD = Transportation Management Division. 
Table A.2-3. Transportation Field (Operations) Experience.

\begin{tabular}{|l|l|l|}
\hline \multicolumn{1}{|c|}{ Experience } & TMD Instructor & \multicolumn{1}{|c|}{$\begin{array}{c}\text { TMD Associate } \\
\text { Instructor } \\
\text { (Team Teach Only) }\end{array}$} \\
\hline $\begin{array}{l}\text { HAZMAT/HAZWASTE } \\
\text { Transportation } \\
\text { Experience Required }\end{array}$ & $\begin{array}{l}160 \text { hours for } \\
\text { qualification }\end{array}$ & $\begin{array}{l}80 \text { hours prior to } \\
\text { or commensurate } \\
\text { with instruction } \\
\text { of TMD courses }\end{array}$ \\
\hline $\begin{array}{l}\text { Recurrent } \\
\text { HAZMAT/HAZWASTE } \\
\text { Transportation } \\
\text { Experience }\end{array}$ & 40 hours annually & 40 hours annually \\
\hline
\end{tabular}

HAZMAT = hazardous materials.

HAZWASTE = hazardous waste .

TMD = Transportation Management Division.

Table A.2-4. Transportation Training.

\begin{tabular}{|l|l|l|}
\hline \multicolumn{1}{|c|}{ Training } & \multicolumn{1}{|c|}{ TMD Instructor } & \multicolumn{1}{|c|}{$\begin{array}{c}\text { TMD Associate Instructor } \\
\text { (Team Teach OnTy) }\end{array}$} \\
\hline Modules 1-12 & $\begin{array}{l}\text { Successful completion } \\
\text { required within last } \\
24 \text { months }\end{array}$ & $\begin{array}{l}\text { Successful completion } \\
\text { prior to or commensurate } \\
\text { with instructing } \\
\text { Modules 1-12 }\end{array}$ \\
\hline $\begin{array}{l}\text { Advanced Waste } \\
\text { Workshop }\end{array}$ & $\begin{array}{l}\text { Successful completion } \\
\text { required within last } \\
\text { 24 months } \\
\text { (Equivalent training may } \\
\text { be approved) }\end{array}$ & $\begin{array}{l}\text { Successful completion } \\
\text { required prior to } \\
\text { instruction of Advanced } \\
\text { Waste Workshop }\end{array}$ \\
\hline $\begin{array}{l}\text { Advanced RAM } \\
\text { Workshop }\end{array}$ & $\begin{array}{l}\text { Successful completion } \\
\text { required within last } \\
\text { 24 months } \\
\text { (Equivalent training may } \\
\text { be approved) }\end{array}$ & $\begin{array}{l}\text { Successful completion } \\
\text { required prior to } \\
\text { instruction of Advanced } \\
\text { RAM Workshop }\end{array}$ \\
\hline
\end{tabular}

NOTE: All other TMD training courses must be successfully completed prior to instructing those specific courses.

TMD = Transportation Management Division.

RAM = radioactive material . 
DOE-0227-2

Revision 1

Table A.2-5. Management Evaluation of Instructor's Presentation Skills.

\begin{tabular}{|c|c|c|}
\hline Evaluation & \multicolumn{1}{|c|}{ TMD Instructor } & \multicolumn{1}{c|}{$\begin{array}{c}\text { TMD Associate } \\
\text { Instructor }\end{array}$} \\
\hline Basic level courses & $\begin{array}{l}\text { One evaluation annually } \\
\text { (if applicable) }\end{array}$ & $\begin{array}{l}\text { One evaluation annualiy } \\
\text { (if applicable) }\end{array}$ \\
\hline
\end{tabular}

- Qualification of TMD Instructors and Associate Instructors, based on the above requirements, shall be documented and/or maintained by TMD-approved personnel.

- TMD-approved transportation training programs shal1 be subject to the following requirements.

- An initial review shall be performed to determine program and instructional effectiveness.

- Initial reviews should be performed by personnel who are not responsible for the development of the program being reviewed. Qualifications of these personnel may be obtained from TMD.

- Ongoing reviews shall be performed at logical intervals by qualified TMD-approved personnel. Resulting data and information (e.g., instructor effectiveness, number and type of classes administered, transportation related occurrences as a result of training) shall be provided through approved personnel to TMD.

- Where TMD-sponsored training programs or instructors are not available to cover a specific transportation training need (e.g., training is being provided by non-TMD Instructors) contractors are responsible for ensuring that such training is developed, documented, and approved. Personnel who require special skills to develop or administer such training (e.g., site-specific criterion) shall have documented qualifications before performance of work. 
- Documentation and records associated with qualifications of personnel who support TMD transportation training programs shall be controlled as follows.

- Documentation and records associated with personnel qualifications shall be distributed, handled, controlled, and maintained according to approved contractor policies and procedures and in accordance with applicable DOE orders and TMD requirements (DOE order 1324.2A).

- Documentation and records associated with personnel qual ifications that are also considered "Qual ity Records" must be maintained in a legible, accurate, and complete manner to ensure that qualified personnel are adequately experienced, trained, and authorized to develop and administer TMD transportation training programs. 
DOE-0227-2

Revision 1

\section{QUALITY ASSURANCE PLAN FOR TRANSPORTATION MANAGEMENT DIVISION TRANSPORTATION TRAINING PROGRAMS}

Title: $\quad$ Systematic Planning

Number: Training Procedure 3

Revision: 1

Date: $\quad 10-01-94$

\subsection{PURPOSE}

This procedure establishes Quality Assurance (QA) requirements for systematic planning.

\subsection{SCOPE}

This procedure provides a methodology for systematic planning of U.S. Department of Energy (DOE), Transportation Management Division (TMD), transportation training programs. Activities that require systematic planning include, but are not limited to, the following:

- Resources

- Time management associated with development and implementation of training programs

- Development of new missions

- Development of procedures

- Procurement of training program materials and services.

\subsection{APPLICABILITY}

This procedure applies to all activities associated with developing and implementing TMD transportation training programs that require systematic planning. 
DOE-0227-2

Revision 1

\subsection{SOURCE REQUIREMENTS}

- 10 CFR 830.120, Quality Assurance

- DOE Order 1324.2A, Records Disposition.

\subsection{DEFINITIONS}

- Contractor. Any contractor, supplier, seller, subcontractor, vendor, consultant, agent, or institution performing work associated with TMD transportation training programs.

- TMD-Approved Personnel. Personnel appointed by TMD who are responsible for coordinating TMD transportation training program development and implementation activities. Approved personnel also coordinate the resolution of occurrences where unsatisfactory work is identified.

- Systematic planning. A systematic arrangement of details and activities associated with development and implementation of TMD transportation training programs.

- TMD Instructors and Associate Instructors. Personnel approved by TMD to develop and administer TMD transportation training programs.

\subsection{RESPONSIBILITIES}

- Contractor. Controls and reports systematic planning efforts associated with TMD transportation training programs.

- TMD. Directs and sponsors all TMD transportation training programs. Reviews and approves all systematic planning activities related to the development and implementation of TMD transportation training programs.

- TMD-Approved Personnel. Personnel appointed by TMD to evaluate contractor systematic $p l a n n i n g$ efforts and communicating them to TMD.

- IMD Instructors and Associate Instructors. Personnel approved by TMD for planning the development and instruction process for TMD transportation training programs. 
DOE-0227-2

Revision 1

\subsection{PROCEDURE}

- Personnel involved in the development and implementation of TMD transportation training programs (e.g., program developers, instructors, coordinators, contractors) shall perform systematic planning with the objective of preventing future problems and improving overall quality of training programs. Planning and problem prevention include, but are not limited to, the following:

- Development of terminal and enabling objectives

- Job and task analysis

- Readiness review

- Peer review

- Review by TMD

- Dry runs of newly developed training programs

- Assessment of outyear training needs

- Review of current training program implementation (advantages and shortfalls)

- Road mapping.

- Planning process reviews (independent assessments) shall be performed by personnel not involved in performing development and/or implementation activities (e.g., peer review, dry-run critique). Independent review, peer review, and a dry run of training program development and implementation activities shall be performed before the training programs are used or before full implementation. Review verifications shall be performed by TMD-approved personnel in accordance with Training Procedure (11), Section 7.0.

- Contractor planning efforts must support those of TMD. Strategic planning, project planning, and budgeting for development and implementation of TMD transportation training programs shall be planned, authorized, accomplished, and formally scheduled in accordance with TMD requirements. Planning and budgeting shall also be integrated horizontally across the range of TMD transportation training programs to establish realistic near-term, midterm, and long-term (outyear) goals. 
- Contractors developing and implementing TMD transportation training programs shall identify, in conjunction with TMD, all performance measurement criteria as part of the planning phase.

- All documentation and records, including "Quality Records" prepared for purposes of planning TMD transportation training programs, shall be prepared, maintained, retained, and controlled in accordance with established DOE orders, contractor policies and procedures, and TMD requirements (DOE Order 1324.2A). 


\section{QUALITY ASSURANCE PLAN FOR TRANSPORTATION MANAGEMENT DIVISION TRANSPORTATION TRAINING PROGRAMS}

Title: Modular Training Performance Evaluation and Measurement Number: Training Procedure 4

Revision: 1

Date: $\quad$ 10-01-94

\subsection{PURPOSE}

This procedure establishes Quality Assurance (QA) requirements for evaluating and measuring training performance.

\subsection{SCOPE}

This procedure provides a method for evaluating and measuring the effectiveness of the U.S. Department of Energy (DOE), Transportation Management Division (TMD), transportation training programs. Activities for measurement include, but are not limited to, the following:

- Development

- Implementation activities

- Training

- Instructional support information (e.g., pre/post course evaluation sheets).

\subsection{APPLICABILITY}

This procedure applies to all activities associated with TMD transportation training programs that can be measured in terms of effectiveness. 


\subsection{SOURCE REQUIREMENTS}

- 10 CFR 830.120, Quality Assurance Requirements

- American Society of Mechanical Engineers (ASME)/NQA-1, Quality Assurance Program Requirements for Nuclear Facilities

- DOE Order 1324.2A, Records Disposition.

\subsection{DEFINITIONS}

- Contractor. Any contractor, supplier, seller, subcontractor, vendor, consultant, agent, or institution performing work associated with TMD transportation training programs.

- Performance Indicators. Process or activity monitoring and analysis tools used to evaluate and measure the success and/or failure of TMD transportation training programs (e.g., performance data, monitoring methods, status indicators, costs, etc).

- Performance Evaluation. Analys is of quality-related information to identify trends that enhance or adversely impact quality.

- TMD Instructors and Associate Instructors. Personne1 approved by TMD to develop and administer TMD transportation training programs.

\subsection{RESPONSIBILITIES}

- Contractor. Establishes and reports, as required, performance evaluation and measurement activities associated with TMD transportation training programs.

- TMD. Directs and sponsors all TMD transportation training programs. Reviews and approves all performance evaluation activities associated with development and implementation of TMD transportation program activities.

- TMD-Approved Personnel. Personnel appointed by TMD to evaluate contractor performance measurement indicators, monitoring methods, and evaluation activities and communicate them to TMD as needed.

- TMD Instructors and Associate Instructors. Personnel approved by TMD to develop and implement performance measurement indicators, monitoring methods, and evaluation activities for TMD transportation training programs. 
DOE-0227-2

Revision 1

\subsection{PROCEDURE}

- Performance data, costs, and other quality-related information associated with the development and implementation of TMD transportation training programs shall be analyzed to identify trends that enhance or adversely affect quality. Trends shall be reported to TMD directly, or through TMD-approved personnel (e.g., failure rates, deviations from procedure).

- Completed tests will be provided to personnel appointed by TMD to perform statistical analysis. When statistics show that a test question has been missed by students on the average of $30 \%$ of the time, the question will be reviewed, revised, or replaced.

Following statistical analysis, tests will be forwarded to appropriate record storage facilities.

- Students feedback will be obtained by phone a minimum of 6 weeks after each TMD class is completed. Personnel appointed by TMD to obtain student feedback will survey $20 \%$ of the students attending each class. Instructors of the class or workshop from which students are being surveyed shall not conduct surveys of that class.

As a minimum, course content, course training aids, and student recommendations will be discussed with students during the survey.

- Monitoring methods used as a basis for performance indicators shall be implemented in a systematic manner to ensure that transportation training program requirements and milestones are achieved in a logical, cost-effective, and timely manner (ASME NQA-1 - 1989 Edition, Supplement 10S-1, 5.2).

- All documentation and records, including "Quality Records," prepared as performance indicators for purposes of monitoring and evaluating TMD transportation training programs shall be prepared, maintained, and retained in accordance with established DOE orders, contractor policies and procedures, and TMD requirements (DOE Order 1324.2A). 
DOE-0227-2

Revision 1

This page intentionally left blank.

TP.4-4 of 4 


\section{QUALITY ASSURANCE PLAN FOR TRANSPORTATION MANAGEMENT DIVISION TRANSPORTATION TRAINING PROGRAMS}

Title: Comment Input and Resolution

Number: Training Procedure 5

Revision: 1

Date: 10-01-94

\subsection{PURPOSE}

This procedure establishes Quality Assurance (QA) requirements for comment input and resolution.

\subsection{SCOPE}

This procedure provides a method for communicating and resolving comments regarding the U.S. Department of Energy (DOE), Transportation Management Division (TMD), transportation training programs.

\subsection{APPLICABILITY}

This procedure applies to all TMD transportation training programs either under development or being implemented.

\subsection{SOURCE REQUIREMENTS}

- 10 CFR 830.120, Quality Assurance Requirements

- DOE Order 1324.2A, Records Disposition.

\subsection{DEFINITIONS}

- Comments. Input received or generated as a result of student or peer review of instructional methodology, training material, and associated documentation. 
- Comment resolution. Satisfactory response to input received from peer or readiness review as determined by TMD, or personnel approved by TMD to make the determination.

- Contractor. Any contractor, supplier, seller, subcontractor, vendor, consultant, agent, or institution performing work associated with TMD transportation training programs.

- IMD-Approved Personnel. Personnel appointed by TMD who are responsible for coordinating TMD transportation training program development and implementation activities. Approved personnel also coordinate the resolution of occurrences where unsatisfactory work is identified.

- Peer review. Review of training methodology, course materials, and associated documentation before official release of the material for use or during use of material.

- Readiness review. The review of training methodology, training materials, and associated documentation to ensure it is fit for use.

- TMD Instructors and Associate Instructors. Personnel approved by TMD to develop and administer TMD transportation training programs. Participates, as required, in peer and readiness reviews regarding training activities on behalf of TMD.

\subsection{RESPONSIBILITIES}

- Contractor. Ensures that input received or generated as a result of student or peer review of instructional methodology, training material, and associated documentation is resolved satisfactorily.

- TMD. Directs and sponsors all TMD transportation training programs. Reviews and approves all activities related to the development and implementation of TMD transportation training programs.

- TMD-Approved Personnel. Personnel appointed by TMD to coordinate the review of training methodology, training materials, and associated documentation. Coordinates the resolution of comments generated as a result of peer and readiness review.

- TMD Instructors and Associate Instructors. Personnel appointed by TMD to participate in resolution of comments generated as a result of peer review or readiness review of training program methodology, course materials, documentation, and associated activities. 
DOE-0227-2

\subsection{PROCEDURE}

- All comments generated as a result of peer review, readiness review, course evaluation sheets, or other shall be forwarded to

TMD-approved personnel for disposition and final resolution and retention on behalf of TMD. All comments shall be dispositioned to the satisfaction of the commentor by TMD-approved personnel in conjunction with TMD. Comment resolution shall be provided to TMD for review. The process of control, review, approval, and revision of comments shall be controlled according to DOE orders and TMD requirements.

- Documentation and records, including "Quality Records", associated with peer review or readiness review comments shall be prepared, maintained, retained, and controlled in accordance with approved contractor policies and procedures, DOE orders, and TMD requirements (DOE Order 1324.2A). 
DOE-0227-2

Revision 1

This page intentionally left blank.

TP.5-4 of 4 


\title{
QUALITY ASSURANCE PLAN FOR TRANSPORTATION MANAGEMENT DIVISION TRANSPORTATION TRAINING PROGRAMS
}

\author{
Title: Regulatory Compliance Review \\ Number: Training Procedure 6 \\ Revision: 1 \\ Date: $\quad 10-01-94$
}

\subsection{PURPOSE}

This procedure establishes Quality Assurance (QA) requirements for regulatory compliance review of training methodology, training materials, and documentation.

\subsection{SCOPE}

This procedure provides a method for ensuring that training methodology, training materials, and documentation for the U.S. Department of Energy (DOE), Transportation Management Division (TMD), are reviewed for regulatory compliance issues against applicable Federal regulations (e.g., 49 CFR, 10 (FR), DOE orders, applicable U.S. Environmental Protection Agency (40 CFR) and Occupational Safety and Health Administration (29 CFR) requirements, TMD requirements, and other regulations and requirements as applicable.

\subsection{APPLICABILITY}

This procedure applies to all training activities, including methodology, course materials, and associated documentation, either under development or being implemented, prepared on behalf of TMD.

\subsection{SOURCE REQUIREMENTS}

- 10 CFR 830.120, Quality Assurance Requirements

- DOE Order 1324.2A, Records Disposition

- 10 CFR, Energy, applicable Parts 0 to 199, current edition

- 29 CFR, Occupational Safety and Health Administration, applicable Parts, current edition

$$
\text { TP. 6-1 of } 4
$$


- 40 CFR, Protection of Environment, applicable parts, current edition

- 49 CFR, Transportation, applicable Parts 0 to 199, and Parts 350 to 399 , current edition

- DOE 1540.1, Materials Transportation and Traffic Management

- DOE 1540.2, Hazardous Materials Packaging for TransportAdministrative Procedures

- DOE 5480.3, Safety Requirements for the Packaging and Transportation of Hazardous Materials, Hazardous Substances, and Hazardous Wastes.

\subsection{DEFINITIONS}

- Contractor. Any contractor, supplier, seller, subcontractor, vendor, consultant, agent, or institution performing work associated with TMD transportation training programs.

- TMD-Approved Personnel. Personnel appointed by TMD who are responsible for coordinating TMD transportation training program development and implementation activities. Approved personnel also coordinate the resolution of occurrences where unsatisfactory work is identified.

- Iraining Program Developer. Approved by TMD to develop TMD training programs based on federal regulations, DOE orders, contractor policies and procedures, and TMD requirements.

- TMD Instructor and Associate Instructors. Personnel approved by TMD to develop and administer transportation training programs.

\subsection{RESPONSIBILITIES}

- Contractor. Performs regulatory compliance review on behalf of TMD and review of training methodology, training materials and documentation on behalf of TMD. Also responsible for reporting review output to TMD.

- TMD. Directs and sponsors all TMD transportation training programs where regulatory compliance review is required.

- TMD-Approved Personnel. Personnel appointed by TMD to coordinate review of training methodology, course materials, and documentation.

- IMD Instructors and Associate Instructors. Personnel approved by TMD to review training methodology, training materials, and documentation for regulatory compliance issues.

$$
\text { TP. 6-2 of } 4
$$


DOE-0227-2

Revision 1

\subsection{PROCEDURE}

- Training methodology, course materials, and documentation associated with training activities shall be reviewed annually against applicable federal regulations, DOE orders, and other applicable policies and procedures to ensure accuracy of information provided.

The review shall be performed by contractor personnel (e.g., training program instructors or developers) and submitted to TMD through TMD-approved personne?.

Continuous improvement of training methodologies, course material, and documentation shall be a criterion for compliance review based on DOE orders and TMD requirements.

A11 formal interpretation of federal regulations, DOE orders, and other applicable requirements and procedures necessary to accomplish TMD training activities shall be initiated through approved personnel with TMD concurrence.

- All documentation and records, including "Quality Records," developed as a result of review or obtaining formal interpretation of regulations and requirements for TMD transportation training programs shall be prepared, maintained, retained, and controlled in accordance with established DOE orders, contractor policies and procedures, and TMD requirements (DOE Order 1324.2A).

- Corrective actions resulting from review of transportation training program methodology or formal interpretation from regulatory agencies resulting in changes to training program activities and materials shall be incorporated into training methodology, course materials, and documentation as soon as possible to ensure accuracy.

- Minor changes with little or no regulatory or requirements impact shall be incorporated, as time permits, into training methodology, course materials, and documentation. After discovery, pending corrective action incorporation, these changes shall be communicated to training program users through approved personnel with approval by TMD. Corrective action incorporation into training methodology, course materials, and documentation shall be effective in the next mandatory revision.

- Significant changes shall be incorporated into training methodology, course materials, and documentation as soon as possible. These changes shall be communicated to training program users through approved personnel with approval by TMD. Corrective action incorporation shall be effective as soon as possible in methodology, materials, and associated documentation. 
DOE-0227-2

Revision 1

This page intentionally left blank. 


\section{QUALITY ASSURANCE PLAN FOR TRANSPORTATION MANAGEMENT DIVISION TRANSPORTATION TRAINING PROGRAMS}

Title: Control of Documentation and Records

Number: Training Procedure 7

Revision: 1

Date: $\quad 10-01-94$

\subsection{PURPOSE}

This procedure establishes Quality Assurance (QA) requirements for control of documentation and records.

\subsection{SCOPE}

This procedure ensures that documentation and records for U.S. Department of Energy (DOE), Transportation Management Division (TMD), transportation training programs are identified and controlled according to applicable DOE orders and other regulations, requirements, and procedures, as required.

\subsection{APPLICABILITY}

This procedure applies to all TMD transportation training programs where control of documentation and records is required.

\subsection{SOURCE REQUIREMENTS}

- 10 CFR 830.120, Quality Assurance Requirements

- American Society of Mechanical Engineers (ASME)/NQA-1, Quality Assurance Program Requirements of Nuclear Facilities

- DOE Order 1324.2A, Records Disposition. 


\subsection{DEFINITIONS}

- Contractor. Any contractor, supplier, seller, subcontractor, vendor, consultant, agent, or institution performing work associated with TMD transportation training programs.

- Documentation. Any written or graphic information that describes, specifies, defines, reports, or certifies activities, requirements, procedures, or results associated with transportation training programs. Examples include, but are not limited to, the following:

- Needs assessments

- Completed course modules [including handouts, viewgraphs, and training materials(e.g., Code of Federal Regulations excerpts)

- Other documentation (e.g., guidance or training program review information)

- This Quality Assurance Plan

- Lesson plans

- Instructor notes

- Course outlines

- Test questions

- Design criteria and documents.

- TMD-Approved Personnel. Personnel appointed by TMD who are responsible for coordinating TMD transportation training program development and implementation activities. Approved personnel also prepare and coordinate the TMD transportation training program documentation and records associated with coordination activities.

- Quality Records. Any transportation training program documentation that furnishes evidence of the quality of items or activities affecting quality of TMD transportation training programs.

- Records. Materials that document operations and activities that may be disposed of only after archival authority is obtained from the DOE.

- TMD Instructors and Associate Instructors. Personnel approved by TMD to develop and administer TMD transportation training programs based on federal regulations, DOE orders, contractor policies and procedures, and TMD requirements. Also prepares TMD transportation training program documentation and records associated with training program development. 
DOE-0227-2

Revision 1

\subsection{RESPONSIBILITIES}

- Contractor. Prepares, retains, and distributes documentation and records associated with TMD transportation training programs.

- IMD. Directs and sponsors a11 TMD transportation training programs where documentation and records are required.

- TMD-Approved Personnel. Personnel appointed by TMD to coordinate the preparation, retention, and distribution of documentation and records associated with TMD transportation training programs on behalf of TMD.

- TMD Instructors and Associate Instructors. Personnel approved by TMD to prepare, retain, and distribute documentation and records associated with TMD transportation training programs according to federal regulations, DOE orders, applicable contractor policies and procedures, and TMD requirements.

\subsection{PROCEDURE}

- The preparation, issuance and distribution, and change of documentation and records that specify quality requirements or prescribe activities affecting quality shall be controlled to ensure that correct documentation and records are being used. Such documentation and records, and changes thereto, shall be reviewed for adequacy and approved for release and distribution by TMD.

- Contractors (e.g., instructors) who prepare documentation and records for TMD transportation training programs shall ensure that sufficient documentation and records are reviewed, approved, and maintained to accurately reflect completed work. Procedures shall be used by all entities who maintain documentation and records. The procedures shall include provisions for retention, protection, preservation, traceability, accountability, and retrievability.

- Special process documentation and records associated with TMD transportation training programs, such as those maintained via computer applications, shall be controlled to ensure retrievability and usability.

- The following types of documentation and records, and others as applicable, shall be controlled in accordance with federal regulations, DOE orders, contractor policies and procedures as applicable, and TMD requirements:

- Data files

- Purchase orders and related documents 
- Course outlines

- Lesson plans

- Specifications

- Vendor-supplied documents

- Applicable procedures and instructions

- Training program modules (completed or under development)

- Course tests and attendance rosters

- Review and assessment documentation

- Other documentation and records required to be controlled in accordance with TMD requirements.

- Revision of documentation and records associated with TMD transportation training programs shall be reviewed and approved by the organization (e.g., contractor, instructors, approved personnel) that originally produced the document(s) or record(s) before release and distribution.

- Superseded or canceled documentation and records associated with TMD transportation training programs shall be replaced in a timely manner by TMD-approved organizations. Superseded or canceled documentation and records shall be designated and marked "Superseded" or "Canceled" and shall be maintained for a specified retention period as prescribed by federal regulations, DOE orders, applicable contractor policies and procedures, and TMD requirements.

- Documentation and/or records considered to be "Quality Records" shall be specified in applicable program documents. Quality records shall be legible, accurate, and completed as appropriate for the activity. 
DOE-0227-2

Revision 1

\section{QUALITY ASSURANCE PLAN FOR TRANSPORTATION MANAGEMENT DIVISION TRANSPORTATION TRAINING PROGRAMS}

Title: $\quad$ Transportation Training Program Design Number: Training Procedure 8

Revision: 1

Date: 10-01-94

\subsection{PURPOSE}

This procedure provides Quality Assurance (QA) requirements for the design of transportation training programs.

\subsection{SCOPE}

This procedure establishes $Q A$ requirements for the review, verification, validation, and approval of design activities associated with U.S. Department of Energy (DOE), Transportation Management Division (TMD), transportation training programs.

\subsection{APPLICABILITY}

This procedure applies to all instructional methodology and materials and associated documentation and records developed and/or implemented in conjunction with TMD transportation training programs.

\subsection{SOURCE REQUIREMENTS}

- 10 CFR 830.120, Quality Assurance Requirements

- DOE Order 1324.2A, Records Disposition

- DOE Order 5480.18, Accreditation of Performance Based Training for Category A Reactors and Nuclear facilities

- DOE Order 5480.19, Conduct of Operations for DOE Facilities 
- DOE Order 5480.20, Personnel Selection, Qualification, Training, and Staffing Requirements at DOE Reactor and Non-Reactor Nuclear Facilities

- QLT-180007, Trainer's Training Manual

- DOE/NE-0102T, TAP 2, Performance Based Training Manua7.

\subsection{DEFINITIONS}

- Contractor. Any contractor, supplier, seller, subcontractor, vendor, consultant, agent, or institution performing work associated with TMD transportation training programs.

- Design changes. Changes or modifications to the methodology of the transportation training programs.

- Design interfaces. Coordination of design efforts between participating organizations involved in the development of TMD transportation training programs.

- Design verification. Overview and assurance by TMD-approved personnel (e.g., personnel with experience in training methodology) that the transportation training program design meets regulations and requirements based on complexity, risk, and uniqueness.

\subsection{RESPONSIBILITIES}

- TMD. Directs and approves all design work associated with TMD transportation training programs.

- TMD-Approved Personnel. Coordinates development and implementation of TMD transportation training programs. Interfaces with contractors, subcontractors, and TMD to ensure design requirements are approved and in place for development of transportation training programs.

- IMD Instructors and Associate Instructors. Personnel approved by TMD to design, develop, and administer TMD transportation training programs. Participates in the design review, verification, and validation process of training program development and implementation. 
DOE-0227-2

Revision 1

\subsection{PROCEDURE}

- Training program design and development (e.g., lesson plans, support material) shall be accomplished using TAP 2, Performance Based Training Manual, and QLT-18007, Trainer's Training Manual, as standards.

- Changes or modifications to training program materials shall be controlled by submitting changes or modifications to TMD-approved personnel for review before the materials are used. The personnel appointed to review materials must be knowledgeable of the TMD Transportation Training Program Quality Assurance requirements.

- Changes or modifications to training program design shall be controlled by submitting proposals through approved personnel to TMD for approval.

- Design interfaces and responsibilities for transportation training programs shall be established through approved personnel with concurrence from TMD.

- Design acceptability for transportation training programs shall be proven via simulated training scenarios (i.e., dry runs) with knowledgeable, TMD-approved personnel in attendance for design verification purposes.

- Design records, maintained to provide evidence that design of transportation training program material (e.g., "Quality Records") was properly accomplished, shall include final output and revisions, important steps or milestones in the process, and sources of training program design input. In addition, design records, including "Quality Records," shall be prepared, maintained, retained, and controlled in accordance with established DOE orders, contractor policies and procedures, and TMD requirements

(DOE Order 1324.2A). 
DOE-0227-2

Revision 1

This page intentionally left blank.

TP. 8-4 of 4 
DOE-0227-2

Revision 1

\section{QUALITY ASSURANCE PLAN FOR TRANSPORTATION MANAGEMENT DIVISION TRANSPORTATION TRAINING PROGRAMS}

Title: Inspection and Acceptance of Transportation Training

Number: Training Procedure 9

Revision: 1

Date: 10-01-94

\subsection{PURPOSE}

This procedure provides Qual ity Assurance (QA) requirements for inspection and acceptance of transportation training program materials.

\subsection{SCOPE}

This procedure establishes $Q A$ requirements for inspection and acceptance of materials prepared for and used as part of or in support of U.S. Department of Energy (DOE), Transportation Management Division (TMD), transportation training programs. Such materials include the following:

- Materials generated in house (e.g., viewgraphs, photocopies, other training-related materials)

- Materials procured from external sources

- Materials reworked to ensure acceptability for use.

\subsection{APPLICABILITY}

This procedure applies to all materials prepared as a part or in support of TMD transportation training programs.

\subsection{SOURCE REQUIREMENTS}

- 10 CFR 830.120, Quality Assurance Requirements. 


\subsection{DEFINITIONS}

- Acceptance criteria. Established standards for use of materials associated with transportation training programs. Standards are based on federal regulations, DOE orders, contractor policies and procedures, and TMD requirements.

- Acceptance testing. Established testing processes demonstrating that materials perform as intended.

- Inspection. The official review of transportation training program materials generated either in house or externally through the procurement process.

\subsection{RESPONSIBILITIES}

- TMD. Approves all acceptance criteria associated with the development and implementation of TMD transportation training programs.

- TMD-Approved Personnel. Personnel appointed by TMD to communicate to TMD the performance and results of all inspection activities, established acceptance criteria, and acceptance testing activities.

- TMD Instructors and Associate Instructors. Personnel approved by TMD to perform inspection activities, establish acceptance criteria, and establish acceptance testing processes used in the development and implementation of TMD transportation training programs. Also responsible for communicating newly established acceptance criteria and results of inspection activities and acceptance testing to TMD through TMD-approved personnel.

\subsection{PROCEDURE}

- Developers and instructors of transportation training programs shall ensure the following.

- Prospective material suppliers shall be evaluated to ensure they can perform in an acceptable manner based on established performance standards.

- Performance standards shall be identified before selection, determination, evaluation, and review of materials. Material suppliers shail be evaluated periodically to ensure they continue to perform in an acceptable manner based on established performance standards. 
- Material shall be inspected as required and compared with acceptance criteria according to established contractor policies and procedures, DOE orders, and TMD requirements.

- Materials prepared in house and externally via purchase requisition shall be inspected upon initial receipt to ensure acceptability for use. Materials prepared in house shall be inspected, before use, by personnel who were not involved in developing the materials.

- Materials and services shall be obtained using procurement procedures authorized by DOE orders, contractor policies and procedures, and TMD requirements.

- When material conditions are considered "adverse to quality," materials shall be repaired or replaced, as necessary, and re-inspected to ensure acceptability for use.

- Acceptance testing of transportation training program materials shall be accomplished before implementation of training programs. Dry runs, pilot demonstrations, or other TMDapproved means of testing materials are acceptable means for acceptance testing.

- Documentation and records associated with inspection and acceptance testing shall be controlled in the following manner.

- Documentation and records shall be distributed, handled, maintained, and controlled in accordance with approved contractor policies and procedures and in accordance with applicable DOE orders (DOE Order 1324.2a).

- Inspection and acceptance testing documentation that are considered to be "Quality Records" shall be legible, accurate, and completed as appropriate to reflect the activity being accomplished. 
DOE-0227-2

Revision 1

This page intentionally left blank.

TP.9-4 of 4 


\section{QUALITY ASSURANCE PLAN FOR TRANSPORTATION MANAGEMENT DIVISION TRANSPORTATION TRAINING PROGRAMS}

Title: Management Assessment

Number: Training Procedure 10

Revision: 1

Date: 10-01-94

\subsection{PURPOSE}

This procedure provides Quality Assurance (QA) requirements for management (internal) assessment of TMD transportation training programs.

\subsection{SCOPE}

This procedure establishes QA requirements for planned and periodic management (internal) assessments of applicable U.S. Department of Energy (DOE), Transportation Management Division (TMD), development and implementation activities that affect the quality of the transportation training programs.

\subsection{APPLICABILITY}

This procedure applies to all development and implementation activities in which continuous improvement and conformance, based on established regulations and requirements, is necessary.

\subsection{SOURCE REQUIREMENTS}

- 10 CFR 830.120, Quality Assurance Requirements

- 10 CFR, Energy, applicable Parts 0 to 199, current edition

- 29 CFR, Occupational Safety and Health Administration, applicable parts, current addition

- 40 CFR, Protection of Environment, applicable parts, current edition 
- 49 CFR, Transportation, applicable Parts 0 to 199, and Parts 350 to 399, current editions

- DOE Order 5480.3, Safety Requirements for the Packaging and Transportation of Hazardous Materials, Hazardous Substances, and Hazardous Wastes

- DOE Order 1324.2A, Records Disposition.

\subsection{DEFINITIONS}

- Integrated quality assurance program. This Quality Assurance Plan and other contractor and/or DOE-sponsored plans that make up a total QA Program used for the development and implementation of TMD transportation training programs.

- Management assessment. Continual, self-initiated, or internal assessment by a line organization of activities associated with the development and implementation of transportation training programs. Self-assessment or internal assessment is documented by TMD or reported to TMD as required.

\subsection{RESPONSIBILITIES}

- Contractor. Develops and implements TMD transportation training programs. Maintains an integrated QA Program that meets compliance standards and identifies, through performance criteria, absolute levels of performance. Reports all TMD transportation training program assessment appraisals, audits, or evaluations to TMD through approved personnel.

- TMD. Approves all transportation training program activities performed by program contractors, program developers, and instructors. Reviews a11 TMD transportation training program assessment appraisals, audits, and evaluations.

- TMD-Approved Personnel. Personnel appointed by TMD to participate in and communicate to TMD the occurrence of TMD transportation training program assessment appraisals, audits, and evaluations. Also provide assessment results to TMD. 


\subsection{PROCEDURE}

- Assessment activities, including appraisals, audits, and evaluations, of TMD transportation training programs shall be performed, documented, and forwarded to TMD annually to ensure compliance issues are addressed, milestones are met, and performance is measured. Existing federal regulations, DOE orders, contractor policies and procedures, and TMD requirements shall be used as criteria for assessment of integrated QAPs. In addition, the integrated QAP used shall be evaluated to ensure it supports compliance concerns and promotes quality (CFRs 10, 29, 40, and 49, applicable parts, current editions and DOE Order 5480.3).

- Assessment activities performed by contractors, and other TMDapproved personnel shall allow for participation by appropriate management and TMD. Overall responsibility for assessment activities shall be retained by management of entities directly responsible for assessment performance.

- Assessment results shall be documented and reported directly to TMD or via TMD-approved personnel. Transportation training program activities that result in a favorable assessment (i.e., not considered adverse to quality) shall be re-evaluated, as necessary, to ensure activities remain in compliance. Followup to ensure resolution and appropriate response shall be performed by responsible organizations.

- Documentation and records, including "Quality Records" associated with assessment, shall be distributed, handled, completed, maintained, and controlled in accordance with approved contractor policies and procedures, applicable DOE orders, and TMD requirements (DOE Order 1324.2A). 
DOE-0227-2

Revision 1

This page intentionally left blank.

TP. 10-4 of 4 


\section{QUALITY ASSURANCE PLAN FOR TRANSPORTATION MANAGEMENT DIVISION TRANSPORTATION TRAINING PROGRAMS}

Title: Independent Assessment Number: Training Procedure 11

Revision: 1

Date: 10-01-94

\subsection{PURPOSE}

This procedure provides Quality Assurance (QA) requirements for independent assessment.

\subsection{SCOPE}

This procedure provides a method for independent assessment of the U.S. Department of Energy (DOE), Transportation Management Division (TMD), transportation training programs using the following:

- Assessment scheduling

- Use of technically qualified personnel in an advisory role

- Use of established assessment criteria

- Tracking of corrective action resulting from assessments

- Assessment response.

\subsection{APPLICABILITY}

This procedure applies to all independent assessment activities associated with TMD transportation training programs.

\subsection{SOURCE REQUIREMENTS}

- 10 CFR 830.120, Quality Assurance Requirements

- DOE Order 1324.2A, Records Disposition. 
DOE-0227-2

Revision 1

\subsection{DEFINITIONS}

- Assessment/performance criteria. Existing federal regulations, DOE orders, contractor policies and procedures, and TMD requirements used as a basis for regulatory compliance and performance evaluation during integrated Quality Assurance P7an assessment activities.

- Independent assessment. Assessments performed by technically knowledgeable entities outside of the function performing actual development and implementation work (e.g., oversight organizations and contractor employees from other government sites).

- Integrated QA Program. This Quality Assurance Plan and other contractor and/or DOE-sponsored plans that make up a total QA Program used for developing TMD transportation training programs.

\subsection{RESPONSIBILITIES}

- Contractor. Develops and implements TMD transportation training programs. Maintains an integrated QA Program that meets compliance standards and identifies, through assessment/performance criteria, absolute levels of performance. Reports a11 independent assessment appraisals, audits, or evaluations of transportation training programs to TMD through TMD-approved personnel.

- TMD. Approves all transportation training program activities performed by contractors, developers, and instructors. Approves and/or sponsors all TMD transportation training program independent assessments, audits, and evaluations.

- TMD-Approved Personnel. Participates in TMD training programs, independent assessment appraisals, audits, and evaluations. Provides TMD with independent assessment results.

\subsection{PROCEDURE}

- Planned independent assessment activities on behalf of TMD, including appraisals, audits, and evaluations of TMD transportation training programs, shall be scheduled by the function performing training program development and implementation work. These assessment activities shall be scheduled before implementation or at least every 2 years. Independent assessments shall allow for participation by approved personnel and TMD. This shall be done to ensure objective evidence of quality achievement as regulations and 
requirements change. As applicable, unplanned independent assessments on behalf of TMD shall take into consideration the status, risk, and complexity of development and implementation methodology. The occurrence and results of planned or unplanned independent assessments, either on behalf of TMD, some other regulatory agency, branch of DOE, or contractor function, shall be communicated to TMD through approved personnel.

- Personnel performing independent assessments on behalf of TMD sha11 act in an advisory capacity to TMD in the following manner:

- Provide peer review of development work

- Monitor work performance

- Identify abnormal conditions in work performance

- Identify actions to improve quality

- Report results of assessment activities to TMD through approved personnel

- Perform dry-run critique.

- Personnel performing independent assessments on behaif of TMD shall be technically knowledgeable regarding training program development and implementation methodology and shall have no direct responsibility in the particular area(s) being assessed.

- Independent assessments performed on behalf of TMD shall be conducted using established assessment/performance criteria based on federal regulations, DOE orders, contractor policies and procedures, and TMD requirements.

- Independent assessment results shall be documented and reported through approved personnel to TMD. Results considered "adverse to quality" shall be prioritized in accordance with appropriate planning techniques and promptly acted upon for resolution by the organization responsible for performing the work on behalf of TMD. Follow up to ensure resolution and appropriate response of corrective actions shall be performed by the responsible organizations with input from approved personnel and TMD.

- Documentation and records, including "Quality Records," associated with independent assessment activities shall be distributed, handled, completed, maintained, and controlled in accordance with approved contractor policies and procedures in accordance with applicable DOE orders and TMD requirements (DOE Order 1324.2A). 
DOE-0227-2

Revision 1

This page intentionally left blank.

TP.11-4 of 4 


\section{DISTRIBUTION}

Number of copies

\section{ONSITE}

10

M. E. Burnside (6)

Central Files

OSTI (2)

Public Reading Room

G3-03

L8-04

L8-07

H2-53 
DOE-0227-2

Revision 1

This page intentionally left blank.

Distr-2 of 2 